\title{
Upgrading Techniques for Quay Walls
}

\section{Mohamed DOUAIRI \\ Delft University of \\ Technology, \\ Delft, Netherlands \\ douairi@gmail.com}

Mohamed, born 1976, is a Master student civil engineering at Delft

University of Technology

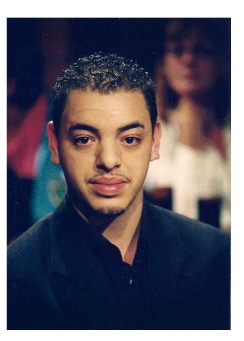

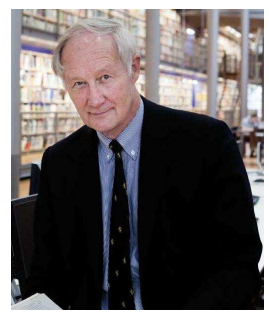

Jarit, born 1947, is Assistent Professor since 2004 at Delft University of Technology

\section{Summary}

The rapid expansion of trade has led to fast growth of handling of goods in many ports. The ports are the catalysts of development of trade and this will result in large future effects.

The increase of ship numbers and sizes will challenge ports in every aspect. Ports have to adapt to the upcoming changes by increasing capacity in every dimension.

Quay walls are one of the most essential components of port infrastructure and with growing volumes of cargo and increasing vessel sizes, the demand on these structures is increasing. Efficient transfer at the quay wall interface is required for the commercial and operational success of any terminal or port. This paper comprises many options for creating extra depth in front of quay walls. Not all presented options have been used in practice.

Keywords: quay wall, anchors, ports, walls, upgrading

\section{Introduction}

Rotterdam is no exception in the trend that can be seen around the world. In the port of Rotterdam there is a trend to move these mooring arrangements towards the sea, where the draughts are deeper. The functionality of those quays outdate in less time than they are designed for. The need for larger depths and vessels is one of the reasons that lead to build 'Maasvlakte 2'.

The question arises, how to deal with these changes. The complete demolition of an existing quay wall construction and replacing by a structure with a larger height is often not possible due to the high costs and / or environmental boundaries. The deepening and upgrading of the existing quay walls is the next option, which means that the

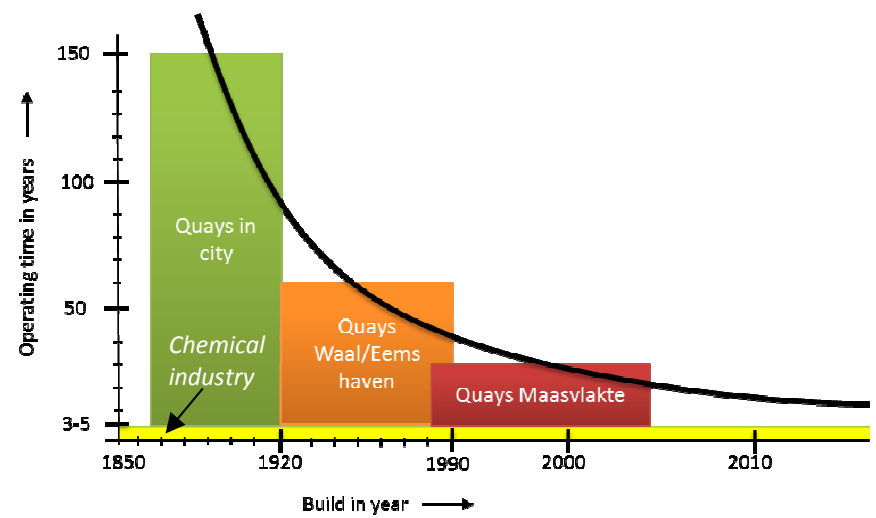

Figure 1: Service life of quay walls in Rotterdam existing quay walls will have to retain more soil then they actually designed for. Berthing bigger ships means also that the quay wall has to sustain increased external forces. Constructive adjustments have to be made to the quay walls, to provide sufficient strength and stability. 


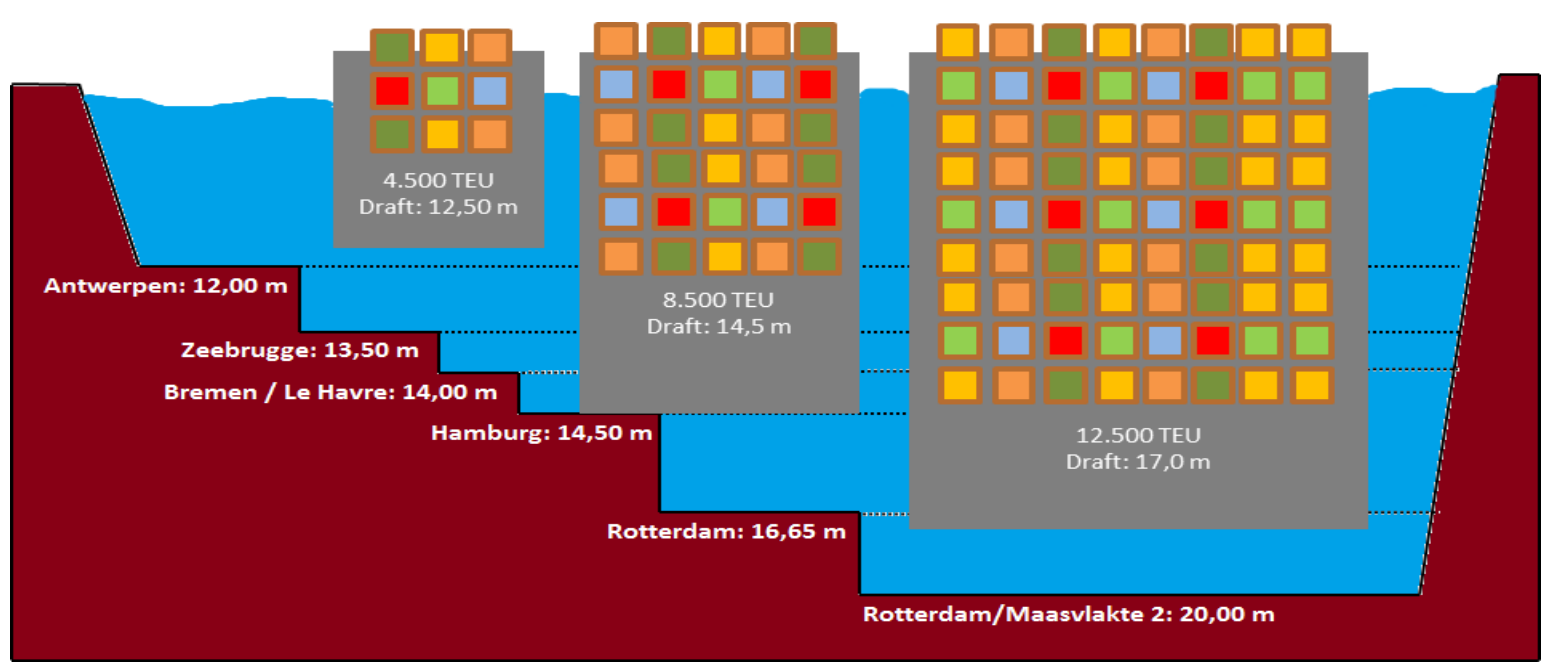

Figure 2: Harbor depth of a few European harbors

\subsection{Quay wall types}

In general quay wall designs can be categorized in three basic designs:

- Gravity walls

- Sheet piles

- Open berth quay walls

These three basic types can be divided into more detailed solutions as shown in Figure 3. Different designs can also be combined to more complex solutions to meet certain requirements, local boundaries and design parameters.

This paper focuses on the design the sheet pile quay walls. The cofferdam and free standing quay wall are left out of consideration, as those designs are not common (see Figure 3, the focus is marked red bold). It is chosen to focus on these types of quay walls as those are the most common quay wall designs for large vessels quay walls. The paper discusses this type of design and gives solutions to deepen and upgrade this type of quay walls. Typical quay walls of this kind of designs given below:

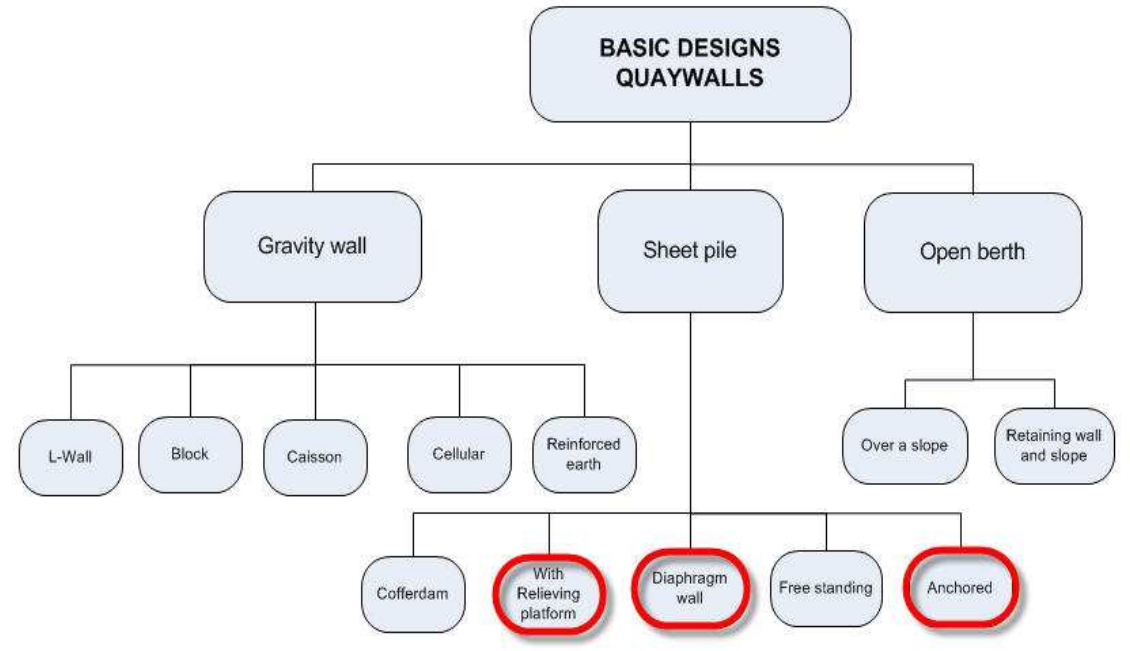

Figure 3: Basic quay wall designs

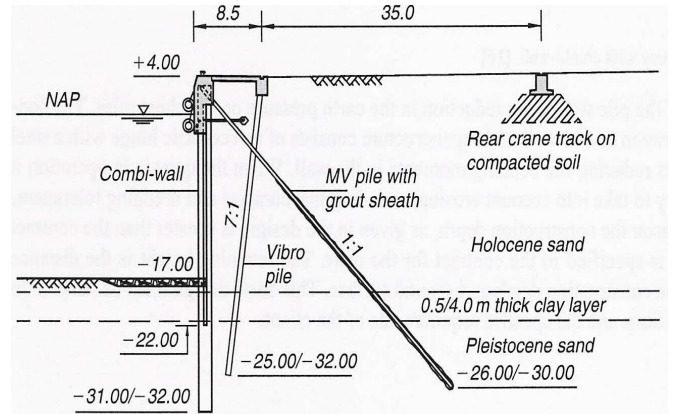

Figure 4: Anchored combined sheet wall (Delta 1A, Amazonehaven)

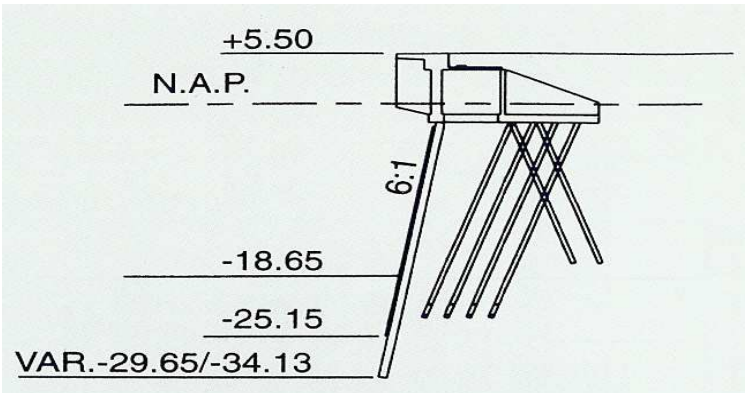

Figure 5: Sheet pile wall with relieving 


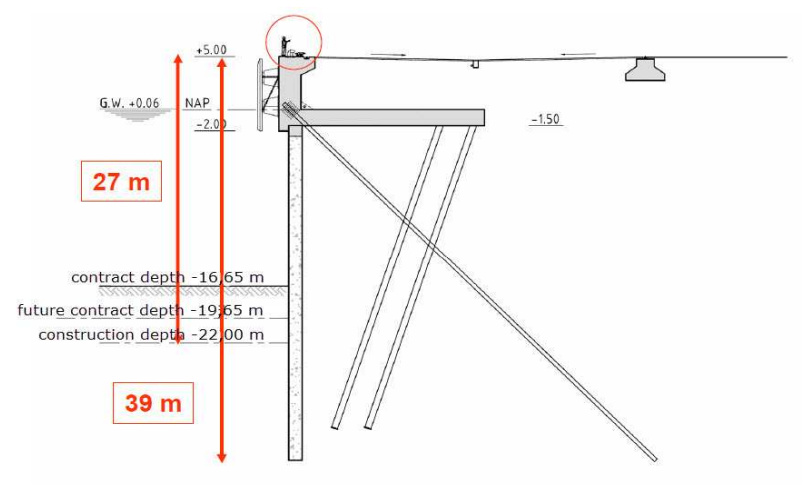

Figure 4: Diaphragm wall Euromax (Yangtze harbor)

\section{Upgrading techniques sheet wall quays}

This problem leads to higher retaining height than the facilities are designed for. As a first approach to this problem conceptual solutions are presented .. To ensure sufficient stability and strength the following general formula can be applied:

$$
S F=\frac{F_{\text {Re } \text { sisting }}}{F_{\text {Driving }}} \geq 1
$$

Assuming that the SF (Safety factor) has to remain approximately the same value (same level of safety) according to equation (1), there are three possibilities to achieve this (see figure 7).

An elaboration of the conceptual solution into

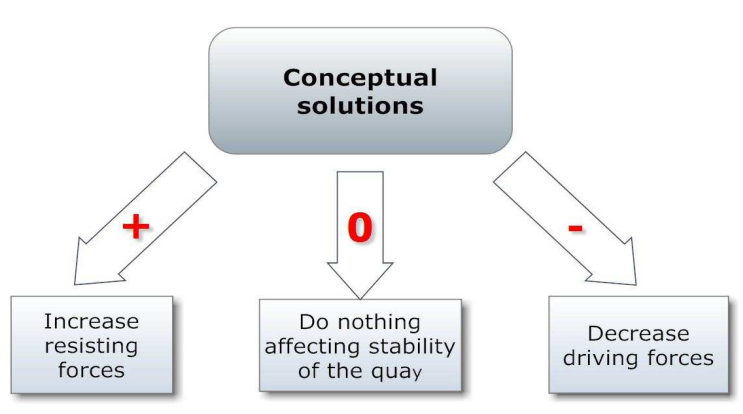

Figure 5: Conceptual solutions more concrete solutions is presented in figure 8.

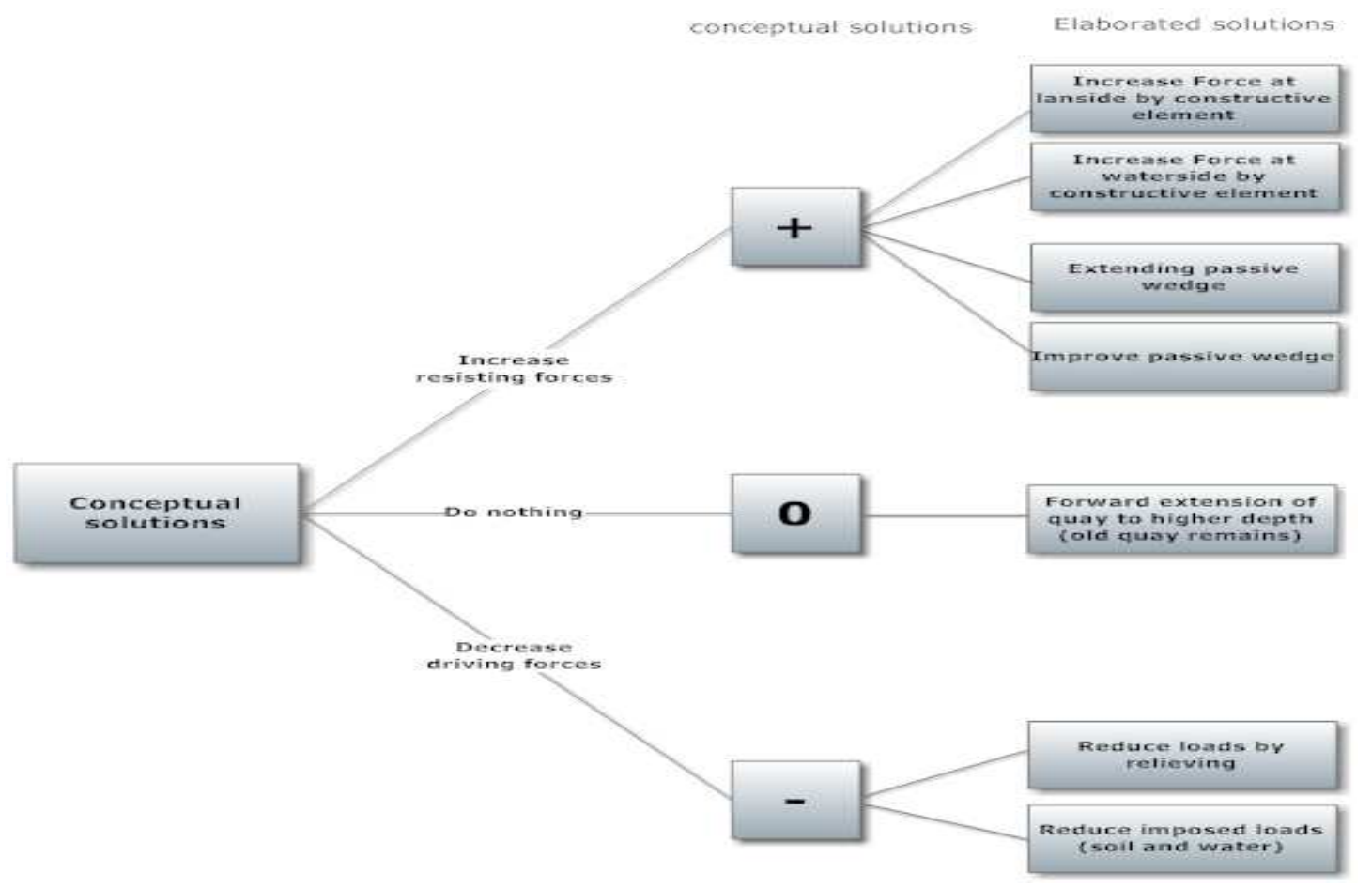

Figure 6: Elaborated conceptual solutions 


\subsection{A variety of solutions}

The elaborated conceptual solutions lead to a variety of solutions. These solutions are presented in the following overview diagrams.
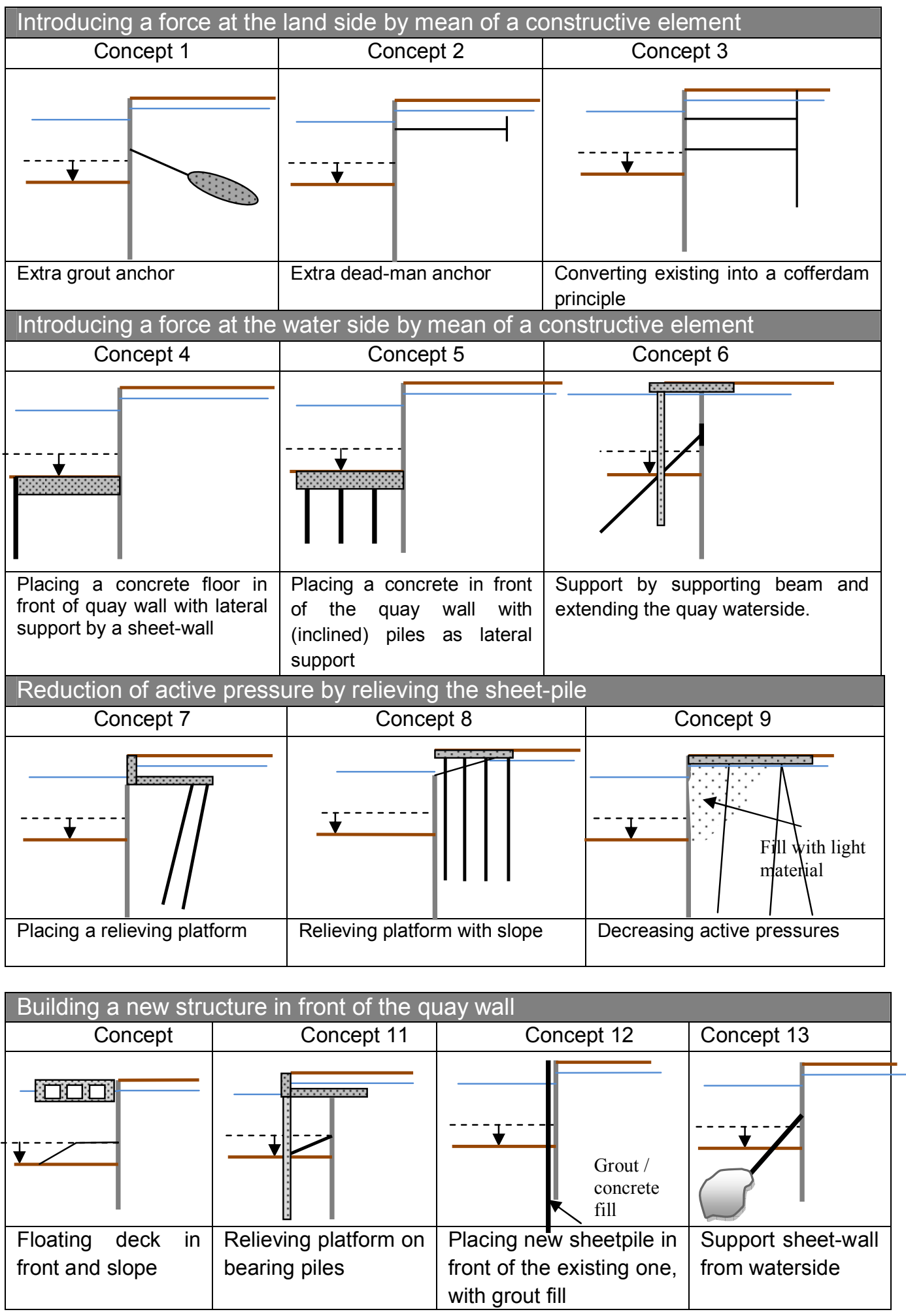

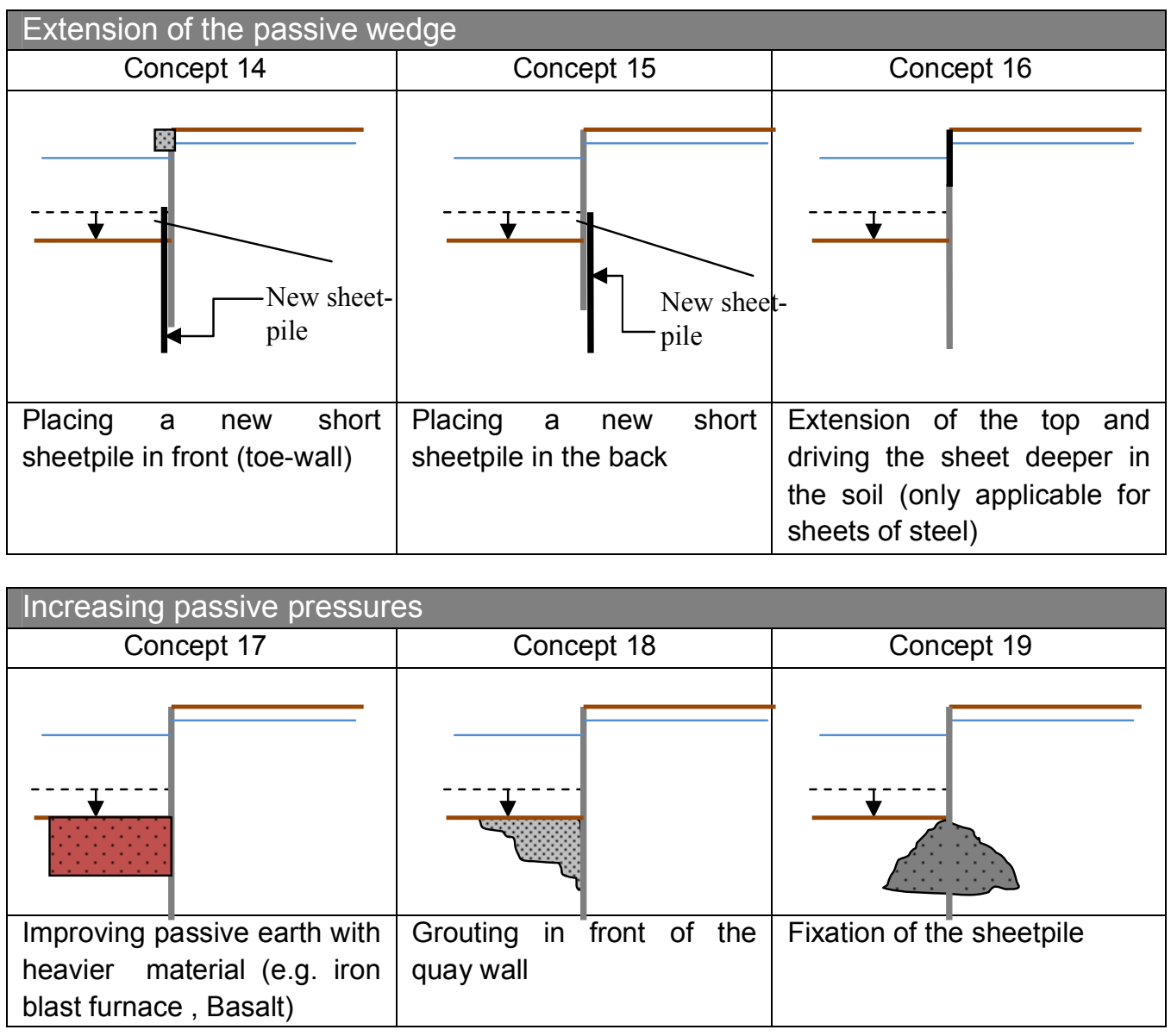

\subsection{Examples of upgrading quay walls at the Maasvlakte}

The presented solutions cannot always be valid for a certain case. The solutions presented converge in most cases to one optimal solution. The optimal solution is mostly found by imposing the specific boundaries and parameters in a given case. In this paper two cases in the Rotterdam harbor are elaborated to find a feasible (technically and economically) solution. A few solutions are validated by the following two cases at the Maasvlakte:

- Anchored combined sheet-wall (see figure 4)

- Diaphragm wall at Yangthze harbor, Rotterdam (see figure 6)

Two different types of quay walls of different materials are chosen. The quay-walls already have a large depth, but it is interesting to see the effect of deepening the waterfront of these type of quay walls. It is chosen to deepen the waterfront of both types with 4 meters and with a higher surcharge load than the quay wall is designed for.

\subsection{Concept solutions: Anchored combined sheet-wall}

To illustrate several options five different solutions for the anchored combined sheet-wall are selected. The solutions are elaborated using hand calculations (Blum model) and use of the Elastoplastic model by means of the software M-sheet.

1) Improving passive wedge with heavy material

2) Light material at landside

3) Extra anchorage 
4) Relieving platform

5) Concrete floor with (inclined) piles

Ad 1) Improving the passive wedge, it chosen for steel slag. Steel slag has Wet unit weight of $\gamma-30 \mathrm{kN} / \mathrm{m}^{3}$, Internal angle of friction of $\varphi=40^{\circ}$, Wall friction of $\delta={ }_{3}^{2} \varphi$, and a cohesion c=0. These properties improve the passive resistance significantly. Implementing the solution leads to satisfying results and the objective deepening. Approximately 3 meters is needed to have sufficient increase of the passive resistance to deepen 4 meters, while the anchorage force doesn't change significantly. This means that no adjustments have to be made to the sheet-wall or to the anchorage. The bending moment in the sheet-wall increases slightly, but still under the allowable representative values of the sheet-wall this particular sheet-wall. To achieve same safety for the bending moment and the shear the stiffness of the sheet-wall could be increased by "adding" material to the cross-section. However, implementing this solution in construction is not an easy task. Excavating the harbor for an extra 3 meters to improve the passive wedge requires relieving of active forces to ensure efficient stability at construction phase. This can be done by excavating at landside and reduce the water pressures. The construction of the solution is very complex and thus can lead to high construction costs.

Ad 2) Using light backfill at landside with low unit weight $\left(\gamma=12 \mathrm{kN} / \mathrm{m}^{3}\right)$ and high internal friction $\left(\varphi=30^{-}\right)$. An objective deepening of 4 meters leads to replacing of 27 meters of soil. The light backfill results in a decrease of the maximum moments decrease of the anchorage force. This solution leads to an extensive excavation of the quay at land side. The solution does lead to decrease of the moments in the sheet-wall but doesn't lead to a satisfying embedment without an extensive excavation of the landside. Apparently, the needed embedment for the sheet-wall is not influenced (marginal effect) by the reduction of earth pressures at landside. Thus the internal stability (strength of the construction) is satisfied by this solution, but doesn't satisfy the external stability without an extensive excavation at landside.

Ad 3) Using extra anchorage leads to satisfying results. The maximum moment in the sheet-wall is reduced significantly. The external stability is also satisfied. However, the modeling of this solution is hard to do, as the behavior of the anchors over time is hard to predict and how this effects the distribution of forces over the anchors and the effect on the quay wall. Also the construction of adding an extra anchor to existing quay-wall is complex. The extra anchor has to be added from waterside below water level.

Ad 4) The relieving platform does substantially reduce the height of the retained soil. Designing the relieving platform on a depth of $10 \mathrm{~m}$ below ground an approximately an excavation of the 3 meters can be obtained, without any modifications neither to the sheet-wall nor to the anchor. Another beneficial aspect of the relieving platform is the ability to build the relieving platform without building a dry dock. The dry dock is formed by the existing sheet-wall during the construction phase.

Ad 5) As can be seen in the results, the concrete-pile system with inclined piles can bear a large force and is useful to reduce the moment in the sheet-wall and to keep make sure that the anchor force doesn't increase after decrease of embedment and applying higher surcharge. The concretepiles system acts as an extra support and reduces the span of the sheet-wall.

The solution given seems to be a technical feasible solution. From construction aspect, a point of concern will be the connection between the concrete floor and the sheet-wall. Another big 
advantage of this solution, there is no need for scour protection. This will reduce the total costs of the solution.

\subsection{Concept solutions diaphragm wall}

For this case three options will be discussed:

1) Heavy material passive side

2) Extra anchorage M.V. Piles

3) Concrete Floor with (inclined) piles

Ad 1) As suggested earlier in this report using heavier material, which improves the resistance to failure of the soil, is not recommended in this case, because this is not the decisive mechanism. Implementing this solution is not the most effective solution to reduce the bending moment in the quay-wall.

Ad 2) Placing the anchor at a level of NAP-14 results in a maximum moment at the level NAP$20 \mathrm{~m}$. Down the level of NAP-20m only two layers of reinforcement is used, which results in a lower capacity of the cross-section. Therefore it can be concluded that the cross section where the maximum moment occurs will fail due bending.

Another point of concern occurs by applying an extra anchorage is that the support by the passive wedge cannot longer be considered as fixed, because of the excavation the passive wedge has not sufficient depth to develop a 'fixed' support, however the mobilized passive resistance is sufficient enough.

Ad 3) The proposed solution of using the floor with inclined piles as an extra support (resisting force) for the increased driving forces lead to decreased moments in the diaphragm wall. Only the maximum moment occurs lower, where the reinforcement is not sufficient.

\section{Conclusions}

- By excavating the harbour bed (increase the retaining height), the decisive mechanism is the internal (strength of material) and external moment stability. These values increase to the third power of the ratio $\mathrm{H} / \mathrm{L}$ (height/total length of the quay). This means that the costs will also increase at higher order.

- Increasing retaining height and the design surcharge is double trouble. This will lead to extensive upgrade of the quay wall. A thought-out of the goal of upgrading is recommended.

- The extra anchorage is technically and from cost-aspect the most feasible solution. This is not surprising as it the only the solution that effectively reduces the span of the quay wall.

- With additional measures for the strength (bending moments) of the quay wall, using heavy material on passive side as a measure upgrading the quay-wall is a feasible technical solution. Further research with more advanced models is needed. Because of the weight of the material, this leads to reduce the scour problem at the quay.

- Solution with concrete floor and inclined piles as a solution to reduce the span of the quaywall is technically feasible solution. The solutions will also serve scour protection. The construction costs of this solution are higher than other proposed solutions.

- Sheet-walls are more flexible for upgrading than a diaphragm wall. This because of the diaphragm wall is not homogenous over the total length. Upgrading such a quay wall needs to be taken into account in the design (as done for the Euromax).

- This study comprised many options for creating extra depth in front of quay walls of which not all have been used in practice. Options 2, 12, 14 and 18 are applied regularly in practice. 


\section{Recommendations}

- Water pressures have the highest contribution to lateral pressure on the quay-wall. Solutions in reducing those pressures can lead to significant excavation of the harbour bed without endangering the strength and stability of the quay wall.

- The different designs of the quay walls are not flexible from upgrading aspects. Therefore it is recommended to think about more flexible solutions that are suitable for upgrading.

- Recommended to investigate the behaviour of a multi anchored quay-wall over time by using FEM models. Multi anchored sheet-walls are common in construction engineering, but rarely used in quay walls.

- Research to heavy weight material with high internal friction is recommended. Proposed in the report iron furnace blast. Further research to this material (or other heavy weight materials) is recommended.

- Calculations for the intended quay wall should always be made taking into account the "current" strength capacity of the quay wall and not from original technical drawings, as materials degrade over time.

\section{References}

[1] DOUAIRI M., "Research into deepening options for quay walls", MSc. thesis Delft University of Technology, 2013

[2] DE GIJT J.G., "Internal note about lifetime of quay wall structures". Rotterdam, 2002

[3] DE GIJT J.G. and VAN DER TOORN A., "Future trends in quay walls design", MTEC 2008, Singapore 